\title{
Optimization of Transportation and logistics costs to maximize revenue and efficiency of supply chain
}

\author{
*Dr. A.K. Damodaram, ${ }^{\#}$ Dr. CH. Lakshmi Tulasi, ${ }^{\$}$ Dr. L. Venkateswara Reddy \\ ${ }^{*}$ \$Professor, *Dept., of ME, ${ }^{\$}$ Dept. of IT, Sree Vidyanikethan Engineering College, Tirupati, India. \\ *damodar_online@yahoo.com, ${ }^{\$}$ lakkireddy.v@gmail.com \\ \#Assoc., Prof., Dept., of M E, Chadalawada Ramanamma Engineering College, Tirupati, India. \\ (chavalimadhavi@yahoo.co.in)
}

\begin{abstract}
Supply chain operations are perceived as total business operations for revenue generation. Various objectives like minimization of total operating costs, minimization of logistics \& transportation costs, maximization of revenue etc forms the necessary pre-requisites for effective and efficient strategies in supply chain practices. But these are conflicting objectives if total efficiency and effectiveness of supply chain performance is to be achieved. Adhering to one strategy does not ensure perceived/improved performance of the supply chain. Therefore, all of such conflicting objectives are to be considered set wise to arrive at the total effectiveness of SCM practices. Supply chain optimization is the optimization using mathematical methods to ensure that the optimal operation of supply chains. Supply chain operations are optimized to minimize operating costs, minimization of inventories, minimization of operating expenses like inventory, transportation, manufacturing, distribution etc. and maximizing gross margin, maximization of revenue, maximization of return on investment. Supply chain operations are optimized to minimize operating costs, inventories, operating expenses like inventory, transportation, manufacturing, distribution, information sharing etc. and maximizing gross margin, revenue return on investment. These costs primarily vary from up-stream side to downstream side as the supply chain entities use customized information sharing facilities and technology. Supply chain optimization may include refinements at various stages of product lifecycle. Supply chain optimization problem is supply chain general problem, i.e. providing products and services to customers at the highest profit, but at the lowest price possible. In this paper, multi-objective optimization of logistics and transportation costs, operating costs and revenue is carried out with the application of Non-Dominating Sorting Genetic Algorithm (NSGA-II). These optimization results are used in decision making \& strategy formulation to develop a cost effective operation of supply chain.
\end{abstract}

Key Words: SCM, Multi-objective optimization, Logistics \& Transportation costs, NSGA-I, Revenue, Objective function sets.

\section{INTRODUCTION}

Optimization in general involve usage of appropriate computer software tools with proper parameter settings. Several customized software is also available to perform optimization with ease. Supply chain problems are complex and difficult due to the number of entities in the supply chains, the lead times at each node of the supply chain, complex inventory management practices at each entity, stochastic demand nature, diversified logistic options etc. Many independent entities in the supply chain each of which try to maximize their own objective functions or interests in business transactions and many of their interests are conflicting when entire supply chain is considered.
Thus, for a specific supply chain, giving an optimal design configuration is very difficult. Any optimization solution to an independent entity does not guarantee a optimal solution to the entire supply chain.

\section{BACKGROUND AND REVIEW}

Supply chain operations are perceived as total business operations for revenue generation. Various objectives like minimization of total operating costs, minimization of Logistics \& Transportation costs, maximization of revenue etc forms the necessary pre-requisites for effective and efficient strategies in supply chain practices. But these are conflicting objectives if total efficiency and effectiveness of 
supply chain performance is to be achieved. Adhering to one strategy does not ensure perceived/improved performance of the supply chain. Therefore, all of such conflicting objectives are to be considered set wise to arrive at the total effectiveness of SCM practices.

Thus the main objective of the supply chain is to maximize the profitability of not just a single entity but rather all the entities taking part in the supply chain. This can only be done if all the entities wish to optimize performance of the supply chain as a whole (system optimization) and do not place their individual preferences (individual optimization) above that of the system. There must also be a complete integration among all the entities so that information can be shared in real-time in order to meet the highly fluctuating demand of the customers. Therefore, to maximize the profitability of the entire supply chain it is definitely not enough to optimize these individual drivers separately. Objective functions capturing these drivers have to be optimized simultaneously.

\section{METHODOLOGY}

In this work, multi-objective optimization using Nondominating Sorting Genetic Algorithm (NSGA-II) algorithm is used to generate pareto-frontier.

\subsection{Multi-Objective Optimization (MOO)}

Given an optimization problem with two or more objectives, MOO will give an optimal trade-off curve between those objectives. All points on this curve are optimal in the sense that it is not possible to improve one objective without worsening at least one other. Note that the trade-off curve is the result of a search in parameter space, and that most solutions will lie behind the Pareto-optimal curve - and may well be of worse quality than the cheapest found by MOO, and more expensive than the best quality solution.

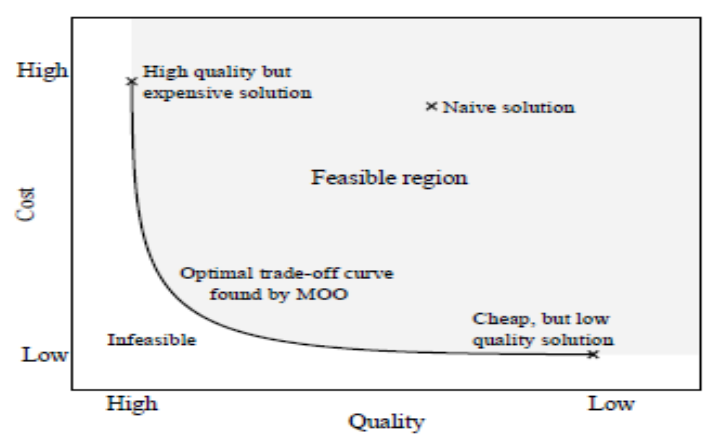

With these results, the decision-maker can make a design choice from among the points on the optimal trade-off curve. Budgetary constraints, quality limits, emission limits can all be taken into account easily by studying the graph. Furthermore the decision-maker can see the shape of the entire curve, and see, for example, for only a small extension of the budget, a large quality gain can be made, or, that if a slightly lower quality than specified is acceptable, large savings can be made.

\subsection{Non-dominated Sorting Genetic Algorithm (NSGA- II)}

A Methodology \& Algorithm presented by Kalyanmoy Deb is used to Optimize the Supply chain Total operating costs, information sharing costs using NSGA-II[16]. A small initial population size is used in the beginning and the population size is increased where at each step the percentage increase in the number of non-dominated solutions with respect to the previous step is noted. If this percentage increase falls below a certain pre-specified amount, then further increase in population size is not necessary.

Srinivas and Deb presented NSGA (Non-dominated Sorting Genetic Algorithm) [23] which was based exactly on MOGA except for a few changes in fitness assignment leaving the rest of MOGA unchanged. NSGA-II is the second version of the famous "Non-dominated Sorting Genetic Algorithm" based on the work of Prof. Kalyanmoy Deb. NSGA-II is a fast and elitist multi-objective evolutionary algorithm. The most recent implementation of multi-objective genetic algorithm is Non-dominated Sorting Genetic Algorithm-II or NSGA-II that is known as one of the best methods for generating the Pareto-frontier. The NSGA-II algorithm ranks the individuals based on dominance. It also calculates the crowding distance for each individual in the new population. Crowding distance gives the GA the ability to distinguish individuals that have the same rank (i.e. those that reside in the same frontier set). Individuals that are in a lower frontier set are considered better than those in higher sets. If they are in the same frontier, then individuals which is the farthest from other individuals is considered better. [90]. The NSGA-II is one of the most competitive multi-objective evolutionary algorithms available today and it's often used as a reference to determine the performance of new approaches [17].

A brief explanation of the steps involved in NSGA-II is presented below:

1. A parent population called $P t$ is randomly generated and an offspring population $Q t$ is created from it.

2. Both populations $P t$ and $Q t$ and combined into population of size $2 N$ where $N$ is the population size. This new population is called $R t$.

3. The population $R t$ undergoes non-dominated sorting where all members are classified and put into fronts.

4. The best $N$ individuals from $R t$ are selected using the crowding tournament selection operator and from the parent population of the next generation $P t+1$. 
5. The steps 1-4 are repeated until the termination criteria have been satisfied.

The source code for NSGA-II is freely available for research purposes at the KanGal (Kanpur Genetic Algorithms Laboratory) website. The code is implemented in the $\mathrm{C}$ programming language. The motivation for using NSGA-II in this paper is because it's performance has been tested on several test functions and has given accurate results in generating the Pareto front as can be seen in Deb et al, 2002 and it is well supported by literature having been used in many real-world applications.

\section{SUPPLY CHAIN OPTIMIZATION - PROBLEM DEFINITION}

A generic supply chain with usual entities is considered Optimization problem to arrive at strategies that help the decision making on effective operation of supply chain. The entities in consideration are five suppliers, three manufacturing plants and four customer zones. In a more general formulation of this problem, the three different components can be supplied by any of the five suppliers. These components can be shipped to any of the three plants where the product is made. Then they are shipped to the customer zones based on the demand.

To mimic a realistic supply chain; some suppliers would be preferred over others depending on their policies which impact their previous performance, quality and timeliness of goods delivered. This argument is also valid in the case of the plants. Similarly depending on the amount of importance that is placed on a certain customer zone it would be beneficial to ensure that supply never falls short of demand at important customer zones, but to an extent it can fall short at less important ones. In this situation however a scenario is considered where only certain suppliers can supply certain plants. Thus they are predetermined and the algorithm required to provide solution does not need to choose suppliers to optimize the supply chain. Instead of a single objective function that is used in most traditional approaches this formulation has conflicting objectives.

A short description of the data values (constants) and variables are presented in this section. The principal set of indices used to denote the entities and the interactions between entities in the supply chain is given in Table 1 .

\begin{tabular}{|l|l|l|}
\hline Index & Meaning & Total indices \\
\hline $\mathrm{i}$ & Component & 3 \\
\hline $\mathrm{j}$ & Supplier & 5 \\
\hline $\mathrm{k}$ & Plant & 3 \\
\hline $\mathrm{l}$ & Retailer Point & 4 \\
\hline $\mathrm{m}$ & Information Sharing & 2 \\
\hline
\end{tabular}

Table: 1. Indices

Using indices, we can derive sets which elicit the interactions between the different entities in the supply chain. These sets are a) Component-Supplier which is represented by (i,j), b) Component-Supplier-Plant represented by $(\mathrm{i}, \mathrm{j}, \mathrm{k})$ c) Plant-Retailer Point represented by(k,l) and d) Information Sharing-supplier-Retailer Point represented by $(\mathrm{m}, \mathrm{i}, \mathrm{j})$.

The Following representations for data are used in this formulation. The data used in this model applied to suppliers, plants, retailer points and information sharing among them.

\begin{tabular}{|l|l|}
\hline Supplier Entity: & \\
\hline Capacity of Supplier ' $\mathrm{j}$ ' for component ' $\mathrm{i}$ ' & $\mathrm{L}(\mathrm{i}, \mathrm{j})$ \\
\hline Cost of making a component ' $\mathrm{i}$ ' by the supplier ' $\mathrm{j}$ ' & $\mathrm{CS}(\mathrm{i}, \mathrm{j})$ \\
\hline $\begin{array}{l}\text { Transportation cost of a component 'i' from supplier } \\
\text { 'j' to plant 'k'/unit }\end{array}$ & $\mathrm{STC}(\mathrm{i}, \mathrm{j}, \mathrm{k})$ \\
\hline Plant Entity: & \\
\hline Capacity of plant ' $\mathrm{k}$ ' & $\mathrm{U}(\mathrm{k})$ \\
\hline Labor cost of plant ' $\mathrm{k}$ '/unit & $\mathrm{LC}(\mathrm{k})$ \\
\hline Manufacturing cost of plant ' $\mathrm{k}$ '/unit & $\mathrm{MC}(\mathrm{k})$ \\
\hline $\begin{array}{l}\text { Plant transportation cost from plant 'k' to customer } \\
\text { zone 'l'/unit }\end{array}$ & $\mathrm{IC}(\mathrm{k})$ \\
\hline Customer Zone Entity: & \\
\hline Demand at customer zone ' $\mathrm{l}$ ' & $\mathrm{D}(\mathrm{l})$ \\
\hline Selling price at customer zone 'l'/unit & $\mathrm{SP}(\mathrm{l})$ \\
\hline Logistics and Transportation Costs: & \\
\hline $\begin{array}{c}\text { Logistics \& Transportation costs between suppliers } \\
\text { and plant }\end{array}$ & $\mathrm{TOC}(\mathrm{j})$ \\
\hline $\begin{array}{c}\text { Logistics \& Transportation costs between plant and } \\
\text { retail points }\end{array}$ & $\mathrm{TOC}(\mathrm{k})$ \\
\hline $\begin{array}{c}\text { A binary variable to represent whether the plant ' } \mathrm{k} \text { ' } \\
\text { gets the component ' } \mathrm{i} \text { ' form the supplier 'j' or not and } \\
\text { this value is fixed }\end{array}$ & $\mathrm{S}(\mathrm{i}, \mathrm{j})$ \\
\hline Total Revenue & \\
\hline
\end{tabular}

Table: 2. Data representations.

\subsection{Variables}

There are three kind of variables used in this formulation: they are vendor shipment variables, plant shipment variable, inventory variables and information sharing variables.

\begin{tabular}{|l|l|}
\hline Variable & Meaning \\
\hline $\mathrm{X}_{\mathrm{i}, \mathrm{j}, \mathrm{k}}:$ & $\begin{array}{l}\text { Amount of component ' } \mathrm{i} \text { ' from supplier ' } \mathrm{j} \text { ' to } \\
\text { plant ' } \mathrm{k} \text { ' }\end{array}$ \\
\hline $\mathrm{Y}_{\mathrm{k}, \mathrm{l}}:$ & $\begin{array}{l}\text { Amount of product shipped from plant ' } \mathrm{k} \text { ' to } \\
\text { customer zone 'l' }\end{array}$ \\
\hline $\mathrm{I}_{\mathrm{i}, \mathrm{k}}:$ & Inventory of component ' $\mathrm{i}$ ' at plant ' $\mathrm{k}$ ' \\
\hline $\mathrm{M}_{\mathrm{i}, \mathrm{j}, \mathrm{k}}:$ & $\begin{array}{l}\text { Cost of Information sharing as a constituent of } \\
\text { Total Operating Cost in supplying component ' } \mathrm{i} \\
\text { from supplier ' } \mathrm{j} \text { ' to plant ' } \mathrm{k} \text { ' and there to the } \\
\text { retailer point }\end{array}$ \\
\hline
\end{tabular}

Table: 3. Variables

\subsection{Optimization Problem Formulations}

The optimization problem is formulated as a two set of two objective function and different sets of constraints depending on which set of objective function is used to represent equalities and inequalities. Various parameter selected for the purpose of Optimization are profit, revenue, 
total operating costs and information sharing costs. The Profit in SC operations refers to the overall efficiency of the supply chain. In order to increase the profit, operating costs have to be minimized to the extent where variable costs are brought to the minimum possible. Revenue, on the other hand refers the ability of the supply chain to ensure effectiveness in business operations and outcomes. A company's performance is measured to the extent to which its asset inflows (revenues) compare with its asset outflows (expenses). While coming to information sharing costs, it refers to the costs associated with the infrastructure, tools and service cost in information sharing practices of a company. Usually, data pertaining to the business entities have to be shared and used for necessary decision making regarding business operations. The up-stream side and down-stream side of the supply chain needs a supportive infrastructure and tools for proper information transfer and sharing.

The following are the expressions for various cost elements.

Logistics \& Transportation Costs from Suppliers to Plants and Plants to Customer Zones;

TC $=$

$\sum_{i} \sum_{j} \sum_{k}\left(X_{i, j, k} S_{i, j} S T C(i, j, k)\right)+\sum_{k} \sum_{l} Y_{k, l} P T C(k, l)$

Total Manufacturing Costs; Which Include Plant labor, Inventory (IC) and Manufacturing Costs

$\mathbf{T M C}=\sum_{k}(L C(k)+M C(k)+I C(k))$

Supplier Costs;

$$
\mathbf{S C}=\sum_{i} \sum_{j}\left(C S(i, j) S_{i, j} X_{i, j, k}\right)
$$

Total Cost of Logistics \& Transportation costs of Suppliers to plants and between plants to Customer Zones (as a constituent of Total Operating Cost)

$$
\begin{aligned}
& \text { TISC }=\sum \sum \sum(\text { ISCj,k }+ \text { ISCk,l }) \\
& \text { Then, Total Operating Costs }(\text { TOC })=\text { TC } \\
& + \text { TMC }+ \text { SC } \\
& \text { Profit }\left(\mathbf{T}_{\mathbf{P}}\right)=\mathbf{T}_{\mathbf{R}}-\text { TOC }
\end{aligned}
$$

\subsection{Objective Function Sets}

The following sets of objective function combinations were selected to help the decision maker/manager on effective operation of a supply chain. Objective functions are paired to enable the selection of suitable strategy to optimize the supply chain. The most considerable key performance indicators for Supply chain efficiency are Profit, Manufacturing costs, Logistics \& Transportation Costs, operating costs and Revenue. An effective and efficient supply chain ensures maximization of revenue and profit and minimization of all costs in business operations. Therefore, it is mandatory to establish set of objective

\begin{tabular}{|c|c|}
\hline $\begin{array}{l}\text { Set } \\
1:\end{array}$ & $\begin{array}{l}\text { Objective Function 1: } \begin{array}{l}\text { Maximize Profit } \\
\text { Maximize Profit }=\mathrm{T}_{\mathrm{p}}\end{array} \\
\begin{aligned} \text { Objective Function 2: } & \text { Minimize Manufacturing Cost } \\
& \text { Minimize }\end{aligned} \\
\mathrm{TMC}=\sum_{k}(L C(k)+M C(k)+I C(k))\end{array}$ \\
\hline $\begin{array}{l}\text { Set } \\
2:\end{array}$ & $\begin{array}{l}\text { Objective Function 1: Maximize Revenue } \\
\qquad \quad \text { Maximize } \mathrm{T}_{\mathrm{R}} \\
\text { Objective Function 2: Minimize Logistics } \\
\text { \& Transportation Costs } \\
\quad \text { Minimize } \\
\mathrm{TC}= \\
\sum_{i} \sum_{j} \sum_{k}\left(X_{i, j, k} S_{i, j} \operatorname{STC}(i, j, k)\right)+\sum_{k} \sum_{l} Y_{k, l} P T C(k, l\end{array}$ \\
\hline
\end{tabular}
functions that supports the decision making meaningful.
The paper considered two set of objectives for optimize the supply chain and is as follows.

Subjected to

Constraints

a) Supplier and Plant Capacity constraints;

$$
\begin{aligned}
& \sum_{l} Y_{k, l} \leq U_{k} \quad \forall k \\
& \sum_{k} S_{i, j} X_{i, j, k}=L(i, j) \quad \forall \mathrm{i}, \mathrm{j}
\end{aligned}
$$

b) Inventory balancing constraints;

$$
\sum_{j} S_{1, j} X_{1, j, k}=\sum_{l} Y_{k, i}+I_{1, k} \quad \forall \mathrm{k}
$$

(3)

$$
\sum_{j} S_{2, j} X_{2, j, k}=\sum_{l} Y_{k, i}+I_{2, k}
$$

$\forall \overline{\mathrm{k}}$

$$
\sum_{j} S_{3, j} X_{3, j, k}=\sum_{l} Y_{k, i}+I_{3, k} \forall \mathrm{k}
$$

(5)

\subsection{NSGA-II}

Non-dominated Sorting Genetic Algorithm is used to optimize the supply chain costs. In order to obtain the idea on stochastic nature of the results obtained through evolutionary computation, a random seed analysis was performed on the objective function in each set. The generation size of 500 and 700 with a population size of 100 is presumed to be the best combination to obtain the trade-off curve. NSGA-II Parameter Settings: Parameter setting for NSGA-II is presented in the following table 4

\begin{tabular}{|l|l|}
\hline GA Settings & 100 \\
\hline Population size & 500 and 700 \\
\hline Number of Generations & 0.9 \\
\hline Cross over Probability & 0.05 \\
\hline Mutation Probability & Binary tournament selection \\
\hline Selection type & Simulated binary crossover \\
\hline Crossover type & Polynomial mutation \\
\hline Mutation type & \\
\hline
\end{tabular}

Table 4: NSGA-II parameter setting 


\subsection{NSGA-II OUTPUT}

The following sections deals with the obtained results of multi-objective optimization results through NSGA-II for each of the objective set functions. Total number of seeds used for each set is 57 .

\subsubsection{Objective function Set 1: Manufacturing costs Vs Profit :}

Random seeds generated for objective functions of manufacturing costs and profit were fed to NSGA-II to obtain the results. Random Seed Analysis is performed for both the objective functions in the objective function sets. For set 3 the table 5 gives the Random Seed Analysis.

\begin{tabular}{|l|l|l|}
\hline & $\begin{array}{l}\text { OBJECTIVE } \\
\text { FUNCTION }\end{array}$ & $\begin{array}{l}\text { CORRESPONDING } \\
\text { VALUE }\end{array}$ \\
\hline Statistic & $\begin{array}{l}\text { Manufacturing } \\
\text { Cost }\end{array}$ & Profit \\
\hline Maximum & 132178.4578 & 26492.8891 \\
\hline Minimum & 41542.21473 & 75610.3701 \\
\hline Mean & 82998.10303 & \\
\hline Standard Deviation & 29096.65754 & \\
\hline $\begin{array}{l}\text { Confidence Level } \\
\text { (95.0\%) }\end{array}$ & 7720.382379 & \\
\hline & Profit & Manufacturing Cost \\
\hline Maximum & 27414.4817 & 136590.8994 \\
\hline Minimum & 7563.7858 & 41553.9033 \\
\hline Mean & 170400.8606 & \\
\hline Standard Deviation & 57690.4351 & \\
\hline $\begin{array}{l}\text { Confidence Level } \\
\text { (95.0\%) }\end{array}$ & 15168.9265 & \\
\hline
\end{tabular}

Table 5 : Random Seed analysis for set 1



Fig: 1. Trade-off Curve between Manufacturing costs and Profit for Population size 100 \& 500 Generations

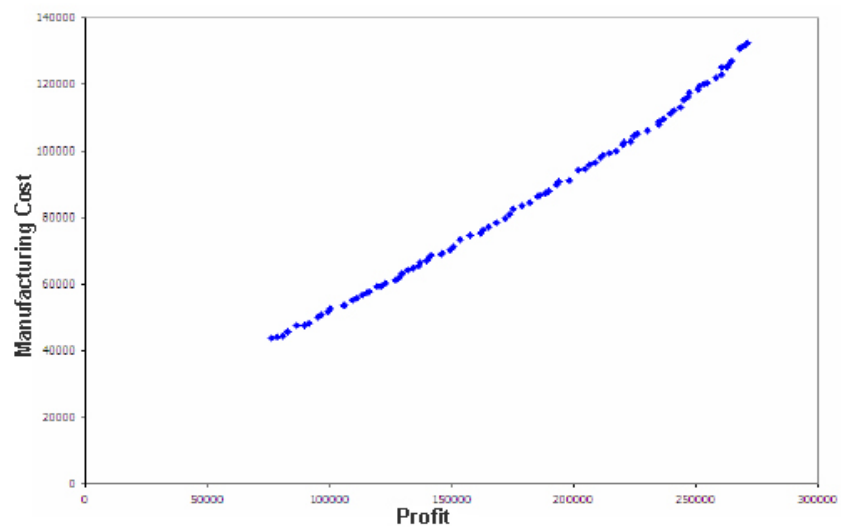

Fig: 2. Trade-off Curve between revenue and logistics and transportation costs for Population size 100 \& 700 Generations.

It is evident that the Patero front of efficient solution given by NSGA-II output is well populated for generations 500 and 700. The Values for manufacturing cost varies between 40000 and 235000 and the values for profit vary between 75000 and 280000. Fixed Costs in the Manufacturing costs leads to the huge threshold value, therefore, the cost assumed here is reflecting the actual scenario in many organizations.

\subsubsection{Objective function Set 2: Revenue and Logistics} and transportation costs:

Random seeds generated for objective functions of Logistics and transportation cost and revenue were fed to NSGA-II to obtain the results. Random Seed Analysis is performed for both the objective functions in the objective function sets. For set 1 the table 6.6 gives the Random Seed Analysis.

\begin{tabular}{|l|l|l|}
\hline & $\begin{array}{l}\text { OBJECTIVE } \\
\text { FUNCTION }\end{array}$ & $\begin{array}{l}\text { CORRESPONDING } \\
\text { VALUE }\end{array}$ \\
\hline Statistic & $\begin{array}{l}\text { Logistics } \\
\text { Transportation } \\
\text { Cost }\end{array}$ & Revenue \\
\hline Maximum & 60753.9689 & 413244.6669 \\
\hline Minimum & 58008.8504 & 399045.7778 \\
\hline Mean & 59277.9656 & \\
\hline Standard Deviation & 879.5506 & \\
\hline $\begin{array}{l}\text { Confidence Level } \\
\text { (95.0\%) }\end{array}$ & 231.2660 & Logistics \\
\hline & Revenue & 60887.6095 \\
\hline Maximum & 413935.9111 & 58009.2044 \\
\hline Minimum & 399047.6089 & \\
\hline Mean & 406155.0645 & \\
\hline Standard Deviation & 4326.7826 & \\
\hline $\begin{array}{l}\text { Confidence Level } \\
\text { (95.0\%) }\end{array}$ & 1137.6695 & \\
\hline
\end{tabular}

Table 6: Random Seed analysis for set 2 


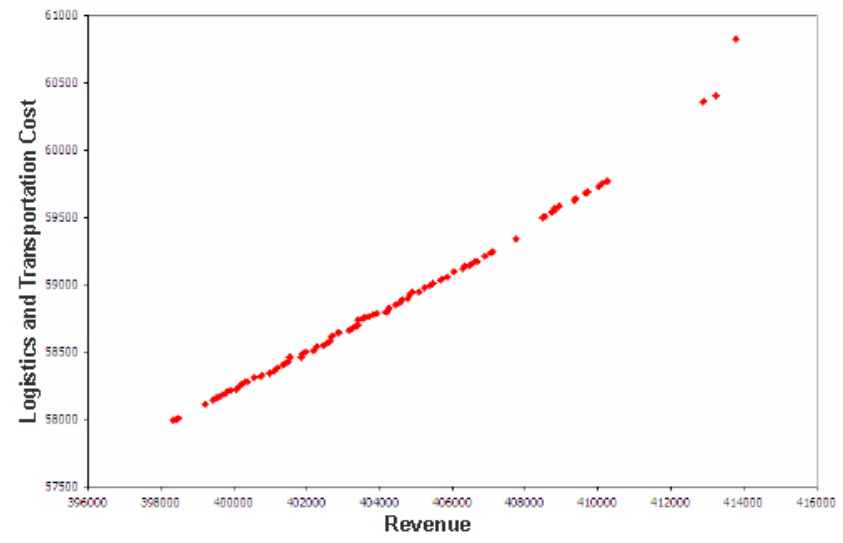

Fig: 6.4. Trade-off Curve between Logistics \& Transportation Cost and Revenue for Population size 100 \& 500 Generations

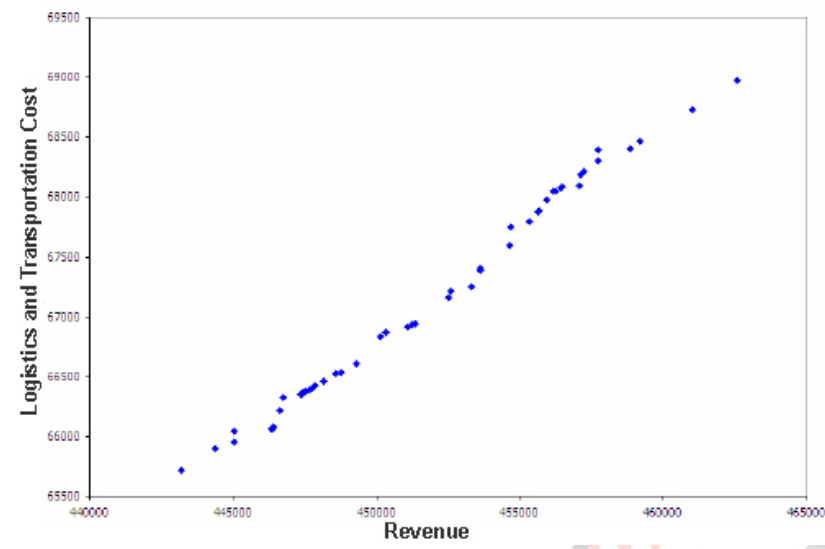

Fig: 6.5 . Trade-off Curve between Logistics \& Transportation Cost and Revenue for Population size 100 \& 700 Generations

It is evident from the figures that the Patero front of efficient solution given by NSGA-II output is well populated for generations 500 and 700. Logistics costs are the costs associated with the scheduling and execution of transportation both in-bound and out-bound logistic activities. There exists a strong relation between the logistics and transportation costs and the revenue because of its criticality in the entire supply chain. Any mismatches will readily affect the revenue generation from the business operations. These mismatches may be due to change in transportation schedules, order delivery etc.,

\section{CONCLUSIONS}

NSGA-II gave good results and provided for a well populated Pareto front which a decision making analysis in choosing the solution that best embodies with each objective function set. The results are presented for generation sizes of 500 and 700. A brief conclusions drawn from the output of NSGA-II is as follows. There exists a strong relation between the logistics and transportation costs (costs in both in-bound and out-bound logistic activities) and the revenue generated because of its criticality in the entire supply chain. Any mismatches will readily affect the revenue generation from the business operations. These mismatches may be due to change in transportation schedules, order delivery etc. However due to decrement of logistics \& transportation costs, efficiency of the supply chain improve.

\section{REFERENCES}

[1] Ales Groznik and Marinko Maslaric, "Achieving competitive supply chain through business process reengineering: A case from developing country African Journal of Business Management Vol.4 (2), pp. 140148, February, 2010

[2] Ales Popovic, Mojca Indihar Stemberger, Jurj jaklic, "Applicability of Process Maps for simulation modeling in Business Process Change Projects", Interdisciplinary Journal of Information, Knowledge and Management, Vol1, 2006.

[3] Beamon, B.M. "Measuring supply chain performance", International Journal of Operations and Production Management, 19 (3), pp. 275 - 292.

[4] Chaim Silberstein,. Microsoft Canada Co. "Supply Chain Management Preparedness Survey" Report \& Analysis , Marc 2006

[5] Chains Rachel Mason-Jones, and Denis R. Towill 'Coping with Uncertainty: Reducing Bullwhip" Behaviour in Global Supply Supply Chain Forum An International Journal , Vol. 1 - 2000 (12)

[6] Damodaram A.K., Ravindranath, K, "Identification of Improvement Opportunities in the application of Information Technology for Managing Global Supply Chains - An Emerging economics Perspective", Proceedings of the IMRC 2008, Global Supply Chain Management-Role of Emerging Economies" IIM Bangalore.

[7] Damodaram A.K., RavindraNath K, "Information Technology usage in Indian companies and Supply chain collaboration and management - a case Study of Indian industries", Proceedings of the 5th International Conference on Logistics \& Supply Chain ManagementILSCM 2010, organized jointly by PSGCT and Central Michigan University

[8] Damodaram A.K., RavindraNath K, "Cloud Computing for Managing Apparel and Garment Supply Chains an Empirical study of Implementation Frame Work", IJCSI, International Journal of Computer Science Issues, Vol. 7, Issue 6, November 2010, P- 325-336 : ISSN Online: 1694- 0814

[9] Fatemeh Haghighat and F. Haghighat "The Impact of Information Technology on Coordination Mechanisms of Supply Chain", World Applied Sciences Journal 3 (Supple 2): 74-81, 2008 (28)

[10] Gary Gereffi Stacey Frederick, "The Global Apparel Value Chain, Trade and the Crisis Challenges and 
Opportunities for Developing Countries", The World Bank Development Research Group Trade and Integration Team April 2010 WPS5281

[11] Gunasekaran A, E.W.T. Ngai, Information systems in supply chain integration and management European Journal of Operational Research 159 (2004) 269-295

[12]Hammer,M., Champy.J., Reengineering the Corporation: A Manifesto for Business Revolution., Harper Collins, London. (Re-engineering definition)

[13]Hui Li and Qingfu Zhang, “ Multi-objective Optimization Problems With Complicated Pareto Sets, MOEA/D and NSGA-II, IEEE Transactions On Evolutionary Computation, VOL. 13, NO. 2, APRIL 2009

[14] Imam Baihaqi, Nicholas Beaumont and Amrik Sohal "Information Sharing in Supply Chains: A Survey of Australian Manufacturing", International Review of Business Research Papers Vol. 4 No.2 March 2008 Pp.1-12

[15] Jayashankar M. Swaminathan, "Modeling Supply Chain Dynamics: A Multiagent Approach," Decision Sciences Volume 29 Number 3 Summer 1998.

[16] Kalyanmoy Deb, A. Pratap, S. Agarwal and T. Meyarivan "A Fast and Elitist Multiobjective Genetic Algorithm: NSGA-II," IEEE Transactions on Evolutionary Computation, Vol. 6(2), pp. 182-197. (47)

[17] Liuying Shen, Jana Hawley, Kitty Dickerson, "ECommerce adoption for supply chain management in U.S.Apparel Manufacturers" Journal of Textile and Apparel, Technology and Management, Volume 4, Issue 1, summer 2004, P. 1-11. (55)

[18] Mehdi Fasanghari, Farzad Habibipour Roudsari and S. Kamal Chaharsooghi, "Assessing the Impact of Information Technology on Supply Chain Management," World Applied Sciences Journal 4 (1): 87-93, 2008

[19] Martin A. Ould, Business Process Modeling \& Analysis for Reengineering \& Improvement, Hoboken, NJ: John Wiley \& Sons Ltd, 2003. (BPR literature)

[20] Mahfoud S W . "Niching Methods," Handbook of Evolutionary Computation, IOP Publishing Ltd and Oxford University Press, pp. C6.1:1- C6.1:4

[21] Mehdi Fasanghari, Farzad Habibipour Roudsari and S. Kamal Chaharsooghi, "Assessing the Impact of Information Technology on Supply Chain Management," World Applied Sciences Journal 4 (1): 87-93, 2008
[22] Rachel Mason-Jones and Denis R. Towill, "Using the Information Decoupling Point to Improve Supply Chain Performance," The International Journal of Logistics Management, Volume 10, Number 21999 Page 13-26

[23] SIDBI, Diagnostic Study, Tirupur Knitware and Apparel Cluster, prepared for Small Industries Development Bank of India, (SIDBI), 2009 (81)

[24] Tayur, Sridhar, Ram Ganeshan and Michael Magazine, eds, 1999, "Quantitative Models for Supply Chain Management”, Boston: Kluwer Academic Publishers

[25] Yandra, Hiroyuki Tamura,"An Integration Of MultiObjective Genetic Algorithm And Fuzzy Logic For Optimization Of Agroindustrial Supply Chain Design”, IEEE Transaction on Evolutionary Computation, 6(2), 182-197

[26]Zadeh, L.A., The concept of a linguistic variable and its application to approximate reasoning. Information Sciences, 8: 199-249(I) 301-357(II).

[27] Toru Higuchi Marvin D. Troutt, "Dynamic simulation of the supply chain for a short life cycle productLessons from the Tamagotchi case", Computers \& Operations Research 31 (2004) 1097-1114 (55). 